\title{
Attitudes of Princess Rahma College Students toward University Violence
}

\author{
Khowla Abd Al-Raheem Ghoneem \\ Assistant Professor, Al-Balqa Applied University, Salt- Jordan \\ Tel: 962-0777/489756Ｅ-mail: khowlagh@yahoo.com
}

Received: December 2, 2011

Accepted: December 8, 2011 Online Published: April 24, 2012

doi:10.5539/ies.v5n3p98

URL: http://dx.doi.org/10.5539/ies.v5n3p98

\begin{abstract}
This study was conducted at the Princess Rahma University College, one of Al Balqa' Applied University colleges and it aims to identify the attitudes of Princess Rahma College students have towards University Violence, by exploring different variables that vary from the level of violence (Low, medium or high), to gender (males or females), educational achievement (excellent, very good, good and satisfactory), academic year (Freshman, Sophomore, Junior and Senior), as well as the type of degree and the financial status

The study sample consists of 242 students. There are 135 males and 107 females randomly chosen from different disciplines of the college. The (AL-Hendy) scale of 2007 for detecting University violence is used and the study consists of (18) paragraphs. The data is analyzed by using the Statistical Analysis Program (SPSS) which calculated the averages, standard deviations and (T) and (F) tests to answer the inquiries of the study.

The study concluded that the tendencies and inclinations of the students towards violence were low. There were statistical differences in the attitudes of the students because of the differences in gender, the differences in the level of educational achievements as well as differences in the academic year. While there were no statistical differences in the economical level or in the type of specializations.
\end{abstract}

Keywords: Attitudes, Violence, University violence

\section{Introduction}

The studies of attitudes are considered one of the important issues worth studying and taken into consideration, especially those related to the students' attitudes towards violence in the universities. This issue, along with the elimination of dialogue and free- speech, has become in certain situations a phenomenon. University violence is a social phenomenon that can not be accepted anywhere, especially in Islamic societies; such as the Jordanian society. Tracing back through history, to the times when Cain killed Able, social violence existed, and continued to exist up to this day. However, with the progress of life in its different materialistic aspects, the methods, causes, and consequences of violence varied.

The subject gained the attention of many thinkers and researchers who decided to study this phenomenon and identify its reasons and causes. It also attracted the attention of governments, political leaders, various civil-society institutions and universities. From here, the role of the scientific research was highlighted in the study of this phenomenon, and solutions and resolutions were urgently called for, especially that violence became a wide-spread phenomenon at universities. The concern escalated when in April of 2010, a student at the Al Balqa Applied University was murdered by a fellow student at the University gates. This incident triggered controversy within the members of the Jordanian society as well as within the various civil and political institutions in Jordan.

\section{Study Objectives}

The study aims to identify the students' attitudes towards university violence. In addition, it aims at recognizing the impact of the students' rates and the level of academic achievement in the formation of the students' attitudes towards university violence. Also the study aims at identifying the financial level (low income, medium and high) and its impact on students. Moreover, the important goals that this study wants to achieve and answer are the effects of gender on the students' attitudes toward student violence. Furthermore; the need to determine whether the specialization and degree, which the students are studying at the Princess Rahma College, have any impact or affect on the attitudes towards student violence. It was also important to identify whether the academic year (freshman, sophomore, Junior and Senior) had any influence on the students' attitudes toward university violence. As noted previously, it is 
important to study these variables and their effect on the students' attitudes towards university violence because upon determining in which directions such attitudes are developing, appropriate and effective solutions can be easily derived.

\section{The Importance of the Study}

The importance of this study is to know and understand the attitudes of Princess Rahma Students' towards the phenomenon of student violence, and try to change these attitudes positively and replace the language of dialogue, discussion and consolidation of democratic values in the students' work at all levels. It also calls for a positive change in the students' state of mind in which violence is to become a rejected phenomenon rather than a mean to solve problems and conflicts. On yet another note; this study is important because it helps shed a light on this trend as a disease needing treatment rather than nourishment, to find effective solutions to it, rather than nurture it beyond control. The importance of this study also lies in the fact that it emerges from an academic point of view to enrich the library of Sociology and Psychology with studies of scientific and practical value that would benefit the researchers and concern institutions on the treatment of such an occurrence. This issue needs ongoing studies that will accompany the evolution of societies and the evolution of forms and methods of violence that develop every day.

What makes this study even more substantial is that it focuses on a specific human segment in the society that needs assistance in order to become a valid block in the society and helps consolidate positive attitudes towards other aspects of the society. The practical point of view of the study lies in:

i. Better planning to improve the students' conditions inside the university campus.

ii. Setting appropriate and possible solutions to eliminate the core sources of the university violence.

iii. Setting appropriate professional and psychological guiding programs to help reduce university violence.

\section{The Problem Facing the Study}

In the light of the present situation; the social and political changes and the direct association with the social, political and economic development of the Jordanian society, this study attempts to know the tendencies of Princess Rahma students towards University Violence through a sample of students, which will also clarify the relation of (gender, level of educational average, financial situation, specialty, academic year) to the students' attitudes towards violence. In other words, this study could be considered as a serious attempt to find out the correct answer to the following questions:

i. What are the students' attitudes towards University Violence?

ii. ii. What is the relationship between gender and students' attitudes towards violence?

iii. What is the relationship between the level of education and the students' attitudes towards violence?

iv. What is the relationship between the financial status of students and their attitudes towards violence?

v. What is the impact of specialization on University Violence?

vi. What is the impact of academic year on student's violent attitudes?

\section{The Study Limits}

Due to the fact that the objective of the current study is to determine the attitudes of Princess Rahma college students towards university violence, it is basically determined by its subject matter. This is a study to the students' attitudes at the Princess Rahma College towards university violence. The targeted samples are college students, and the tools used to conduct the study were test $(\mathrm{T})$ and test $(\mathrm{F})$. Student averages and standard deviations were also taken into consideration and they were extracted through the statistical analysis program (SPSS). Time and circumstances were also looked into and the time of occurrence was determined during the first semester of 2010/2011. The venue was another aspect that was considered and it was at the Princess Rahma College campus. Thus, the dissemination of the study results should be regarded carefully and such limitations are to be cautiously noticed.

\section{The Study Hypotheses}

The students' attitudes towards university violence as the previous studies have shown can be positively dealt with. The category of students who suffered from this problem can improve and will therefore, in return improve their academic results and their educational average. The null hypotheses of the study can be formulated as follows:

i. What are the attitudes of the Princess Rahma College students towards university violence (high, medium, low)?

ii. No statistical differences in students' attitudes towards violence at the level $(0.05=\alpha)$ because of gender differences. 
iii. No statistical differences in students' attitudes towards violence at the level $(0.05=\alpha)$ because of the difference in the financial situation (low, medium, high).

iv. No statistical differences in students' attitudes towards violence at the level $(0.05=\alpha)$ because of the reduction of students educational average level.

v. No statistical differences in students' attitudes towards violence at the level $(0.05=\alpha)$ because of the differences in the type of specialization.

vi. No statistical differences in students' attitudes towards violence at the level $(0.05=\alpha)$ because of the differences in the academic year (first, second, third and fourth).

\section{Study Terms}

Definitions of "Attitudes":

- (Allport Floyed Henry) defined "Attitudes" as "A nervous mental state of readiness organized by personal experiences and works to guide the individual's response to the things and situations that relate to this readiness."

(Morgan) defined it as "The tendency of the individual response toward or against the subject or person or idea."

- While (Newcomb) sees that the attitude "Is not a response but a steady tendency to some extent to respond in a certain way to something or a certain situation."

- (Thurstone) on the other hand, believes that Attitude is "The degree of positive or negative feelings associated with some psychological subjects." (Hawamdeh, 2010).

The definition of "Violence":

Violence linguistically refers to "The harm or distress or force and unjustified intimidation for the words or the meanings of a specific text. Some common references that attribute to certain reactions are "complex, highly emotional and violent). The most extreme would be "Deadly violence" which refers to death resulting from acts of violence." (Hawamdeh, 2010).

- The student violence could be defined procedurally as being "patterns of offensive or compulsive behaviors including physical and psychological abuse, economic exploitation and destruction of properties by students against their peers or their teachers at the university."

\section{Theoretical Framework}

Violence is considered as an acquired deviational behavior arousing worry because it is remarkably spread in this age and time. It has become a bad social phenomenon increasing day by day with its manifestations and forms, and the underlying factors behind its appearance are deepening and its implications vary. Violence is considered one of the first manifestations of behavior known to human societies, but the rates have significantly increased in recent decades. New forms of violence appeared in which no society is free. Recently, violence has become a widespread phenomenon in our Arab society, especially in educational institutions. Through a review of social and emotional studies on the attitudes regarding this particular subject, it was found that psychologists and sociologists gave it a great importance in addition to the workers in the field of Human Sciences. Moreover, these studies gave a lot of point of views and theories that explain different aspects of human behavior, particularly violence and its motives. In addition to that, Islam in its modern conception and its call to maintain the human dignity and rights, forebode violence in all its forms, whether it is verbal violence; by ordering us not to mock and ridicule others, or physical, by explicitly stating that every Muslim by blood, wealth and honor, is forbid to harm or kill other Muslims. In the following part of this study, the attitude of violence and its concepts and reasons will be discussed.

\section{Previous Studies}

There are many studies that addressed the violence issue at universities:

In a study of Abu Zuhri, Ali (2005).This study aimed at knowing the Attitudes of Palestinian students towards University Violence. To achieve this, the researchers applied a questioner to sample concise of (365) students in all the universities in both Gaza and The West Bank. The study aimed at knowing the attitudes of Palestinian students toward violence at their universities, and to achieve that, the researchers applied a questionnaire that contained a scale to measure students' attitudes. The results indicated that there is a high level of the student's attitude toward violence at the Palestinian universities. Moreover, there is a relationship between the level of violence and some variables such as, religion, age, university and location. Therefore, the researchers recommended that there must be a higher attention to students at universities for the non-curriculum activities, to minimize the level of violence between them. 
In a study Sarayreh, Khaled (2009) Where the aim of the study identify the reasons which leading to students' violence against teachers and administrators in Jordanian public secondary schools from the students', teachers', and administrators' points of view. The study sample was randomly selected and consisted of 945 individuals: 100 administrators, 200 teachers, and 645 students. In order to collect data, a questionnaire was made and consisted of two sections: one aimed to collect the necessary demographic data about respondents and the other aimed to measure the reasons behind students' violence. The study results have showed that the degree of reasons existence leading to students' violence against teachers and administrators in Jordanian public secondary schools was medium. The order of point views of all individuals of the study sample was as following: external reasons (political and media-related) came at the beginning. Second, school, and finally, psychological reasons came last.

In the Bani Arshead and others (2009) study entitled "The Causes of University Violence in the Jordanian Universities" the causes of violence in Jordanian universities from the perspective of Al-Balqa Applied University students, were uncovered and analyzed. In particular, the study aimed at answering the following questions: What are the causes of violence in Jordanian universities from the perspective of Al-Balqa Applied University students? Are there statistical differences in regards to the variable of gender? Are there statistical differences related to the causes of violence from the point of view of Al-Balqa Applied University students due to the variable of the type of specialization (Science College and Humanities College)? Are there statistical differences on the causes of violence from the point of view of Al-Balqa Applied University students associated with the place of residence (rural, nomadic, city)? Are there statistical differences on the causes of violence from the perspective of Al-Balqa Applied University students attributed to the academic level at hand? Are there statistical differences attributed to the mother's or the father's educational level and background? The study group consisted of students from the Al-Balqa Applied University colleges and the study sample consisted of (800) randomly selected students from the different colleges of the university. The study utilized a questionnaire as a tool to collect data and information, and it reached a list of results that answered its inquiries. Some of the evident causes of violence as reflected by the study were the lack of religious and moral commitment. Familial disintegration was another reason that helped to trigger violent behaviors. As for the gender variable, it was in favor of females. However; variables of specializations and degrees, were in favor of humanity colleges rather than any other. Concerning the place of resident, there were not any noted statistical differences when reviewing this particular variable. On the other hand; regarding the academic level and achievements, it was in the favor of seniors, juniors and sophomores compared with freshman. Regarding the variable of the father's level of education, there were no statistical differences to be noted. Unlike the variable of the parent's educational level of the mother which was in the favor of the students whose mothers carry a college diploma.

Shorbaji's (2008) study entitle "Attitudes of University Students towards Violence and its Relationship to the Religious Commitment and Human Rights Awareness," which applied to students of Education, Literature, and Science colleges as well as a few mixed colleges at the University of Taiz. The study concluded that the attitudes of the University of Taiz students towards violence were negative, and the male percentage was higher than females. The level of religious commitment among the students of the University of Taiz was generally high, and students of the Faculty of Arts showed less commitment comparing to students of the Science and Education faculties. As the study concluded, the students of the Education College were less aware of the human rights of students from the faculties of Arts and Sciences. The study recommended the need to boost the role of universities and educational institutions to spread awareness of the culture of dialogue and the importance of renouncing violence. It should be noted that the study targeted (282) students from the Faculty of Education, (101) of the students of the Faculty of Arts and (97) students from the Faculty of Science and the males percentage was (44\%) to (56\%) females.

In the study of Al-Louzi and Farhan (2009) entitled " Student's Violence at the University of Jordan," The results of a field study of student's violence at the University of Jordan indicated that the most common causes of student's violence on campus from the point of view of the researchers was related to kinship tendency, masculinity, fear of punishment, inappropriate socialization and poor investment of leisure time. The study examined attitudes of undergraduate students at the University of Jordan towards the causes of students' violence and its consequences, culture and violence, and proposed solutions to contain this phenomenon. The most notable results of the violence were stigmatizing the university with a reputation of being a haven for uncontrollable violence. Not to mention the destruction of University property, and the negative impressions left by such acts on the foreign students. In addition, the feeling of lack of feeling it generates on campus. On a final note, researchers considered violence immoral and that it goes against the teachings of Islam and Christianity, human values, and society's expectations of students. The survey data has been collected from a proportional stratified sample composed of (629) students. Utilizing a questionnaire, the data was analyzed by the social science statistical package, using descriptive statistics including frequencies, percentages and averages to describe the characteristics of the participants in the questionnaire as well as the use of Statistics qualitative, including the variance's single analysis. 
Tarawneh's (2008) study has shown that (30\%) of university students were, in one way or another, involved in fights on campus. A study entitled "Risk Factors in the University Environment to the University Students in Jordan," assured that the Jordanian universities did not succeed with their roles and functions to control violence on their campuses maybe due to the lack of having realistic missions and visions, and lack of governance and transparency, competition and equality, and remoteness from international standards in their work. With regards to the causes of fights and quarrels, the survey which included 4 thousand students from (19) governmental and private Universities, reported that it is due to personal reasons, as fourth of the sample emphasized that it was because of the harassment to other female students or female relatives. The forms of student violence had varied ranging from fights between students, staff and harassment, and cell phone harassment, harassment of the common, and disturbance in the lecture, but the most common form is the individual fighting. 73 of students witnessed a quarrel or a form of a fight inside the university. A third of the sample emphasized that their involvement in the fights was limited in the university fellowship to the quarrelling individuals. According to one tenth, their involvement was with the individuals of the same departments and colleges. While the blood relation and the tribal or clan relevant did not constitute to more than one seventh and less than one fifth of the students survey in the study.

In Almkhariz's (2006) study about the violence in the universities, the researcher dealt with this phenomenon by objective analysis that led to findings that pointed the failure of the Higher Education Ministry and universities departments as well as the student affairs deans in dealing with such issues. This study aimed at investigating the phenomenon of student's violence in the public universities in terms of its spreading and its causes and the role of Student Affairs deanships in dealing with such issues when they erupt. The study confirmed that the degree that violence was spreading within university students was alarming even though it was of medium level in general, even in different forms like verbal and physical violence and attacks on property. The verbal and non-verbal came in the front of the forms of violence followed by physical abuse and attacks on property, and the degree of the reasons of student's violence influence was medium in all areas of these reasons. The reasons related to the faculty members and the policy of the university and their administrations have come in the lead as the social, psychological and political reasons have come less effective. The application of the student's sanctions instructions and the use of commissions of inquiry, and neglecting the problems and avoiding them, as well as fighting corruption, mediation and patronage are the most commonly used methods in dealing with students' violence from the perspective of students and administrators. It was noted that any guidance from faculty members to students and trying to make them become aware of laws and regulations of the university and listening to the students proposals and opinions was the lesser-used method or tactic when dealing with violence from the their point of view.

Al-Fuqaha's (2001) study pointed the "Students' Attitudes towards University Violence" in his study by following the survey's relational approach, and by using a scale developed by him with the help of some of the already used standards inhalers to fit the other communities, the study applied to a sample represented a mere (22.8\%) of the Philadelphia University students which attended the morning program only. The students were distributed according to the degree and their tendency to violence and aggressive behavior as follows: Stateless tendency to violence and aggressive behavior (\% 47.5), and few that showed a tendency to violence and aggressive behavior (\% 44.3), and an average in the tendency to violence and aggressive behavior (8\%) and are very much in the tendency to violence and aggressive behavior (\% 0.2). As it appeared, there was a statistical correlation between the degree of propensity to violence and aggressive behavior of the students of the University of Philadelphia and the following independent variables: gender, grade point average, and the number of family members. However; the college and family income variables did not have any statistical effect in the degree of the tendency to violence and aggressive behavior of the students.

In the Khammash and others (1999) study, which dealt with the merits of violence in the University of Jordan and which was conducted on (394) students, the study found that tribal fanaticism and personal differences, and making passes on fellow female students, student council elections, and leisure time spent by the student at the university, as well as the lack of awareness and improper education were mostly the main reasons of fights and quarrels, in other words, violence took place. Most of the students who were involved in fights were from the Faculty of Social Sciences and Law Students, and with low accrual rates in their university studies in addition to the rates of high school, the study showed that the university violence phenomenon is still very limited compared with the number of students.

\subsection{Foreign Studies}

The particular study was carried out by Spenciner and Wilson in (2003). It uncovered the relationship between exposure to chronic community violence, psychological distress and academic performance. The research sample consisted of (385) university students and measured the exposure to community violence and psychological distress with especial scales for this purpose. The study also measured the academic performance through school persistence, and the grade point average. The results showed that there were no statistical correlation between exposure to 
community violence and academic performance, while no positive correlation between exposure to community violence and psychological distress was evident. In addition to this, it showed a relationship between psychological distress and school perseverance, while there is no relationship between psychological distress and the grade point averages.

The results of (Bryant and Spencer, 2003) ended with the application of Domestic Violence Blame Scale on a sample of university student volunteers but the males were more to blame for domestic violence than females.

Each of (Flannery and Quinn - Leering, 2000) concluded that violence results from two cases in which can help faculty members contribute in promoting the mental health of students: the first case to be identified is the fact that most students have some experience with violence, and may need help in dealing with negative effects. Second, intervene against violence and crisis.

The aim of the study which was conducted by Nancy Shook and her colleagues (Shook, et al 2000) was set to reveal the violence resulting from courtship violence among university students. In order to achieve that, a modified version of the Conflict Tactic Scale was used to measure the expression of verbal and physical aggression among a sample of (572) university students, in which (395) were females and (177) were males, who happened to be in a dating relationship over the past year. The results have indicated that (82\%) of the total sample decided that they could indulge in a form of verbal aggressive behavior during a set of meetings with the other through the past year. While (21\%) of the sample decided that they actually indulged in physical aggressive behavior. The results have also shown that females were used to the physical strength of males, it turned out that both sexes have known aggression and were subject to it while growing up from their parents.

The study carried out by Marcus and his colleagues (Marcus, etal. 2000), which was conducted over a period of (3) years, aimed at disclosing interpersonal violence among university students. The study has been designed to detect the following: To identify the prevalence of violence among students, identify the impact of gender - male or female to physical violence. It also aimed at limiting the number of injuries resulting from violence, to make recommendations to improve the policy on the campus, and to reduce violence on university campus. The study sample consisted of (385) university students (200 male, 185 female). The results showed that $(32.7 \%)$ males and $(17.3 \%)$ of females had been subjected to at least one physical act of violence or offence in the past six months. It also brought notice to the fact that males fight in bars and on campus, while females quarrel in complete secrecy in their homes. It also showed that $(9 \%)$ of students suffered injuries that required medical attention. The researcher has finished the research with several proposals, one of them was the need to penalize the conflict with the laws of the university.

The study, which was conducted by Angela McGee (McGee, 1998), tried to detect self-esteem as an indicator of attitudes toward violence among a sample of (271) male and female university students who were from African origins. The Culture Free Self-Esteem Inventory has been applied to assess the status of self-esteem and violence scale for measuring attitudes toward violence. In addition to that, the study aimed at testing the hypothesis, which stated that there was a negative relation between self-esteem and attitudes towards violence. Special data was also obtained with grade point averages, income, place of residence, residence within the university campus, the status of the family, and the educational status of parents. The results have shown using multivariate analysis, that there are statistical differences in social and self-esteem and approval on the war - one of the violence scale dimensions and found statistical differences according to the variable of gender which was in favor of males for the approval of corporal punishment of children, and the approval of social violence, and approval on the war.

The study, which was conducted by Diana Kelly (Kelly, 1997), aimed to reveal the relationship between early exposure to personal and collective violence and academic achievement among a group of American university students of African origins. The study variables included the following: the social and economic positions, academic records, and exposure to personal and collective violence, point of control, and the educational aspirations and expectations, in addition to campus security, and academic and social integration. Students' achievements had been measured through the grade point averages, and the results have shown a negative relationship between exposure to personal and collective violence and academic achievement.

Hendricks-Mathews (1997) has reached through his research that assistance and support should be offered to the medical students who have had personal experiences of family violence to overcome their emotional needs and responses to their patients who are victims of violence. Then he suggested that medical schools should hold and conduct training sessions for the care of self-physical, psychological, emotional, and mental health of students. 


\section{The Study Approach}

The researcher used the descriptive analytical approach in order to obtain the needed data and information to answer questions and hypotheses related to the study, which resorted to previous studies and researches in order to review the attitudes in the study and to come up with methods to better treat and resolve this phenomenon.

\subsection{The Study Group}

This study consisted of Princess Rahma University students. Thus, the study group was of undergraduate students, males and females who varied between freshmen, sophomores, juniors and seniors as well as intermediate university students, first and second years and from different disciplines studied at the college.

A questionnaire was utilized and it consisted of (18) questions and paragraphs divided into two parts. The first part consisted of demographic information, which met the needs of the study and the second paragraph of the study was used in the (Al Hindi, 2007) study.

\subsection{The Study Sample}

The study sample was selected randomly from the study group and consisted of (242) students, divided into different disciplines and different years of study.

\subsection{Study Design}

Questionnaire was used as a tool to achieve the objectives of the study and this study included (18) paragraphs, to further review the student's attitudes towards violence at universities.

\subsection{The Study Variables}

Two groups of variables were set for the study (independent variables, dependent variables).

The independent variables were (attitudes of violence, gender, academic achievement, economical level, academic specialization and academic year).

The dependent variables were the response of the study sample that is Princess Rahma College students towards university violence.

\subsection{The Study Procedures}

The study was conducted in accordance with the following procedures:

i. The researchers distributed 250 questionnaires in total to all disciplines, which were (4).

ii. The questionnaire was compiled and returned to the researcher after the students filled them out. The damaged ones or those that were not filled out properly were disregarded.

iii. The number of valid ones were (242) out of (250) and they had all been returned to the researcher.

iv. The analysis and void of the results of the questionnaires were considered by using the (SPSS) program.

v. The results of the study were written down and further discussions, interpretations, and recommendations were formulated.

\subsection{The Tool Validity}

The researcher used university students' violence scale which is in the (Al-Hindi, 2007) study after reviewing many especial violence scales mentioned in the previous studies. Al-Hindi designed it and accounted its validity and consistency transactions. After presenting Al-Hindi scale, as well as a number of other especial scales, to a number of professors who are also referees and teachers in the educational colleges in the Jordanian universities, this scale had been selected. It consists of (18) smooth, easy, understandable expressions for the students society and short phrases, to encourage students to answer the items on the scale. The scale was made up of five scales as follows: very much agree (given five degrees), agree (given four degrees), neutral (given three degrees), does agree (given the two degrees), and does not agree at all (given the degree of one). The scores ranged between (18) and (90) degrees. The high degree Indicated high violence behavior, while the low degree indicated reduced violence behavior.

- The study sample distribution according to gender:

Table (1) shows the distribution of the study sample according to the students' gender:

Through the table, we note the increasing number of males' percentage more than females in the study sample by (11.4).

- The study sample distribution according to the variable of age:

Table (2) shows the age distribution of the study sample: 
From the data collected in the table we note that the higher age group in the study is (18-20 years) because the age to join university is after (18) years, and students of the intermediate university degree will probably be (20) years.

- The study sample distribution according to specialization:

Table (3) shows the distribution of the study sample according to specialization in Princess Rahma University College. We note from the table that the study sample had covered all disciplines of Princess Rahma University College.

- The study sample distribution by income level and table number (4) shows that:

We note from the table that the largest percentage of the study sample is when the average income reaches (40.45) followed by low-income by (38.01).

- The sample members' distribution by the level of academic achievement and Table (5) shows the level of academic achievement for the study sample:

Through the table we note that the largest percentage of the study sample is from the good level and the percentage $(33 \%)$, and the lowest was weak $(9.5 \%)$.

- The sample members' distribution by the academic year and Table (6) shows the academic year of the study sample: We note from the table that the largest percentage of the study sample was of the freshmen and by (42.56), followed by the sophomore by (30.99). This is due to the greater percentage of Princess Rahma students that are among the first and second year because of a diploma or intermediate university degree, where years of study in the system are two years diploma.

\section{Discussing the Results}

Attitudes of Princess Rahma students toward violence within the university as stated in the questionnaire for the following questions:

\subsection{First Hypothesis}

The attitudes of Princess Rahma students toward the violence in Jordanian universities. Table No (7) Shows the attitudes of the students in answering the questions.

Through the table above we note that the attitudes in the study sample toward the exercise of violence was low and this is consistent with what (Khammash, 1999), (Alfokha, 2001) and (Shorbaji, 2008), reached. However; it differed from what was noted in the (Abu Zuhri, 2005) study. It must be noted that the number of universities in Jordan, between the public and private, is more than (20).

\subsection{The Second Hypothesis}

There are no statistical differences between the students' attitudes toward student violence in reference to gender (male, female). Table (8) shows the averages and deviations of the study sample.

Through the information contained in the table, we reject the nihilism hypothesis and accept the alternative hypothesis, which says that there are statistical differences influences on the attitudes of students towards violence in reference of gender (males and females).

\subsection{Third Hypothesis}

There are no statistical differences between students' attitudes toward violence as a result of economical level differences in terms of income (low, medium, high). Table No. (10) Shows that to calculate differences between the averages the researcher has used a single variate analysis to determine the differences between the scores averages of students attitudes on an attitudes scale as a whole as the economical level variable, and that can be illustrated in table No. (11):

Through the table (11) we note the lack of statistical differences to the level of violence associated with the material level so we accept the nihilism hypothesis and this is consistent with (Abu Zuhri, 2005) and with (Alfokha, 2001). It can be concluded by saying that it does not have to be the poor who is closest to violence, but even low material strata of the society could have habits, traditions and sense of social interdependence which they were residents of rural areas, and thus conclude that the violence attitudes have incorporeal conditions.

\subsection{Fourth Hypothesis}

There are no statistical differences in the students' attitudes toward violence because of the students' academic level difference (weak, satisfactory, good, very good, and excellent). Table No. (12) Shows the level of academic achievement for the study sample as well as and standard deviations. 
To calculate the statistical differences between the averages single variant, analysis were used and shown in table no. (13) That:

Through the table, by comparing students' attitudes of the weaker level with students of excellent level, it became clear that there are statistical differences toward violence in favor of the students with weak academic achievements. This is consistent with the conclusion reached by (Khammash, 1999), (Alfokha, 2001 ) and (Jean Kelly, 1997) and differ with (Spenciner and Wilson, 2003) so we reject the nihilism hypothesis which says that there are no statistical differences at the level of significance as a result of academic achievement and level difference. We, in that case, will have to accept the alternative hypothesis that could be explained as follows: The academically excellent students have few periods and usually spend most of their time in the university library and with subjects that will serve their academic excellence. In return, we find the students of weak grades suffer from long free time and gather in private groups and often practice various types of verbal violence in universities.

\subsection{Fifth Hypothesis}

There are no statistical differences in the students' attitudes toward violence in reference to specialization, specialty, and degree of preference. Table No. (14) Shows the averages and deviations of the study sample according to the variable of specialization.

We note from the table that there are no statistical differences in the students' attitudes toward university violence because of specialization difference. Thus; we accept the nihilism hypothesis and reject the alternative hypothesis which says that there are a relation of statistical significance as a result of specialization difference in spite of (Alfokha, 2001) studies and (Khammash, 1999) study which indicated to the concentration of violence in the universities in the faculties of humanity, but it seems that the sample of the study which focused on university college, the social humanitarian disciplines, left an effect on the students' behaviorism toward university violence.

\subsection{Sixth Hypothesis}

There are no statistical differences in the students' attitudes towards violence because of the academic year difference. Table (15) shows averages and deviations of the study sample for the academic year in college.

Through the table, we note statistical differences of violence attitudes among college students as a result of the academic years difference, so we reject the nihilism hypothesis and accept the alternative hypothesis which confer that there are statistical differences in the results of academic years difference in the students attitudes toward violence, and can be explained by stating that the students of third and fourth year arrived at the maturity of better thinking because of the academic years that they spent in college which raised their awareness and culture in finding solutions to their problems through dialogue, and this is consistent with the conclusion reached by (Abu-Rashid, 2009).

\section{Conclusion}

The students' violence in the university community is considered a bad phenomenon, which must be dealt with by all means possible and available to reach universities free of violence in all its forms verbal, physical. However, this will only be through opening the doors of the democratic dialogue between the community of students and between students and the faculty at universities and establishing the educational values in the university student's life.

Students' violence usually results a negative effects, which reflected on the life of university student and his/her relations in addition to material losses in the university assets. Moreover, what makes things even worse when this violence accompanied by psychological impacts on the rest of the students who were not involved in students' violence. As a result of all these negative effects, this study came to cover these aspects and identify students' attitudes toward the phenomenon of violence in Jordanian Universities.

\section{Recommendations}

i. The researcher recommends intensifying, raising the level of guidance and education in universities in general, and holding seminars and conferences.

ii. Engage students in open dialogues between the departments; the university professors and students in a way to ease the psychological tensions among students.

iii. Apply instructions, laws and regulations related to students' violence with justice and away from patronage.

iv. Spreading religious awareness among students regarding good treatment between Muslims and non-Muslims and the sanctity of Muslim blood on other Muslim.

v. Integrating students of weak averages in the curricular activities organized by the Student Affairs deanships in a way that allows removing the barriers between excelled students and unsurpassed. 
vi. Establish the values of dialogue and democracy in the student's communities instead of tribalism tendency.

vii. Educate students and teach them the importance of finding solutions to their problems away from using violence and away from using violent means.

viii. Educating students in particular to stay away from provocative actions.

ix. Insistence on the penalties on the students who resort to harassment and adverse female students, the thing that leads to violent problems.

\section{References}

Abu Zuhri, A. Z., et al (2005). The attitudes of the Palestinian university students toward violence and their practicing level to it (Master Dissertation, Al-Aqsa University, January 2008). Dissertation Abstracts International, Al-Aqsa University Journal Volume XII, $1^{\text {st }}$ ed. [Online] Available: http://www.alaqsa.edu.ps/ar/aqsa_magazine/files/170.pdf

Al-Fuqaha, I. (2001). The level of the tendency towards violence and aggressive behavior for students at the Philadelphia University. Dirasat: Educational Sciences, 28(2), 480-501

Al-Hindi, Z. Y. (2007). Violence in a changing world ( $1^{\text {st }}$ ed), Vol4. Saudi Arabia: Umm Al-Qura University.

Al-Louzi, Salah H., \& Farhan, Yahya I.(2009). Students' Violence at the University of Jordan. Jordan Journal of Social Sciences, 2(2), 2009- 277

Almkhariz, L.S. (2006). "The phenomenon of student violence in Jordanian universities, their causes and the role of the Deanship of Student Affairs to deal with it. Unpublished doctoral dissertation. Amman Arab University. [Online] Available: http://www.ammonnews.net/article.aspx?articleNO=3880

Bani Arshead, M. N., et al. (2009). The causes of university violence in the Jordanian universities. Al-Sult: Al-Balqa Applied University, Faculty of Princess Rahma university.

Bryant, Aneta \& Spencer, Gale. (2003). University students' attitudes about attributing blame in domestic violence. Journal of Family Violence, 18(6), 369-376. [Online] Available: http://www.citeulike.org/user/JasBrown/article/6052606

Flannery, D., \& Quinn-Leering, Kathleen. (2000). Violence on college campuses: Understanding its impact on student will-being. Community College Journal of Research and Practice, 24(10), 839-855. http://dx.doi.org/10.1080/10668920050179835

Hawamdeh, K. (2010). Violence in the Jordanian Universities. Field Study. Jordan: Social Sciences college, Zarqa Private University.

Hendricks-Matthews, M.K. (1997). Ensuring students' well being as they learn to support victims of violence. Academic Medicine, 72(1), 46-47.

Kelly, Diana, F. (1997). The influence of violence upon academic achievement among African American first time college students. Unpublished Ph.D. Dissertation. The Louisiana State University and Agricultural and Mechanical College.

Khammash, M.D., et al. (1999). Violence in the University of Jordan. A field study. Amman: Social Sciences college, University of Jordan.

Marcus, R.; Reio, T.; Kessler, L.; Cutler, K., \& Fleury, J. (2000). Interpersonal violence between college students: Proximal influences. Paper presented at the Annual Convention of the American Psychological Association (108th, Washington, DC. August 4

McGee, Angela, C. (1998). Campus violence: Self-esteem as a predictor of attitudes toward violence among African American first year College students. Unpublished EDD Dissertation. Temple University.

Sarayreh, Khaled. (2009). The reasons for the directed student violence behavior against teachers and administrators in the Jordanian governmental secondary schools from the perspective of students, teachers, administrators. The Jordanian Journal of Educational Science, 5(2), 137-157.

Shook, Nancy, Gerrity, Deborah, Jurich, Joan, \& Segrist, Allen (2000). Courtship violence among college students: A comparison of verbally and physically couples. Journal of Family Violence, 15(1), 1-22. [Online] Available: http://psycnet.apa.org/psycinfo/2000-15339-001. http://dx.doi.org/ 10.1023/A:1007532718917

Shorbaji, N. A. K. (2008). Attitudes of university students toward violence and its relationship to religious commitment and awareness of human rights. Unpublished doctoral dissertation. University of Taiz: Department of Psychology. [Online] Available: http://www.acofps.com/vb/showthread.php?t=3638 
Spenciner, R., \& Wilson, W. (2003). Impact of exposure to community violence and psychological symptoms on college performance among students of color. Adolescence, 38(150), 239-249..

Tarawneh, A., et al. (2008). Risk factors in the university environment in the Jordanian university community. an academic study published.

Zahran, H. A. S. (2003). Social psychology $\left(6^{\text {th }}\right)$. Cairo: Alam Al kitab.

Table 1.

\begin{tabular}{|l|l|l|}
\hline Gender & Number & Percentage\% \\
\hline Female & 107 & 44.3 \\
\hline Male & 135 & 55.7 \\
\hline Total & 242 & $100 \%$ \\
\hline
\end{tabular}

Table (1) shows the distribution of the study sample according to the students' gender.

Table 2.

\begin{tabular}{|l|l|l|l|}
\hline Age group & Number & Percentage\% & Total \\
\hline $\mathbf{1 8 - 2 0}$ & 107 & 44.21 & \multirow{2}{*}{$100 \%$} \\
\cline { 1 - 3 } $\mathbf{2 1 - 2 3}$ & 103 & 42.56 & \\
\cline { 1 - 3 } More than 24 & 32 & $13: 22$ & \\
\cline { 1 - 3 }
\end{tabular}

Table (2) shows the age distribution of the study sample.

Table 3.

\begin{tabular}{|l|l|l|}
\hline Specialty & Number & Percentage\% \\
\hline Special Education / Bachelor & 59 & 24.38 \\
\hline Social Service / Bachelor & 62 & 25.61 \\
\hline Delinquency and crime/ Bachelor & 58 & 23.96 \\
\hline Special Education / Diploma & 63 & 26.03 \\
\hline Total & $100 \%$ \\
\hline
\end{tabular}

Table (3) shows the distribution of the study sample according to specialization in the Princess Rahma University College.

Table 4.

\begin{tabular}{|l|l|l|}
\hline Economical level & Number & Percentage\% \\
\hline Low & 92 & 38.01 \\
\hline average & 110 & 45.45 \\
\hline High & 50 & 20.66 \\
\hline
\end{tabular}

Table (4) shows the study sample distribution by income level. 
Table 5.

\begin{tabular}{|l|l|l|}
\hline level of academic achievement & Number & Percentage \\
\hline Excellent & 21 & 8.6 \\
\hline Very Good & 74 & 30.5 \\
\hline Good & 82 & 33 \\
\hline satisfactory & 42 & 17.3 \\
\hline weak & 23 & 9.5 \\
\hline
\end{tabular}

Table (5) shows the level of academic achievement for the study sample.

Table 6.

\begin{tabular}{|l|l|l|}
\hline The Academic Year & Number & Percentage \\
\hline Freshmen & 103 & 42.56 \\
\hline Sophomore & 75 & 30.99 \\
\hline Junior & 45 & 18.59 \\
\hline Senior & 15 & 6.19 \\
\hline Total & 242 & $100 \%$ \\
\hline
\end{tabular}

Table (6) shows the academic year of the study sample.

Table 7.

\begin{tabular}{|l|l|l|l|}
\hline The statement & $\begin{array}{l}\text { Number } \\
\text { paragraphs }\end{array}$ & Average & Standard Deviation \\
\hline Attitudes of students' violence & 18 & 2.36 & 0.53 \\
\hline
\end{tabular}

Table (7) Shows the attitudes of the students in answering the question.

Table 8.

\begin{tabular}{|l|l|l|l|}
\hline Gender & Number & Average & Standard Deviation \\
\hline Males & 135 & 3.22 & 0.73 \\
\hline Females & 107 & 1.5 & 0.61 \\
\hline \multicolumn{2}{|l}{ At the level of significance $(0.05=\alpha)$} \\
\hline
\end{tabular}

Table (8) shows the averages and deviations of the study sample.

Table 9.

\begin{tabular}{|l|l|l|l|l|l|}
\hline $\begin{array}{l}\text { Source of } \\
\text { variation }\end{array}$ & $\begin{array}{l}\text { Sum of } \\
\text { squares of } \\
\text { deviations }\end{array}$ & $\begin{array}{l}\text { degrees of } \\
\text { freedom }\end{array}$ & $\begin{array}{l}\text { the average of } \\
\text { squares of } \\
\text { deviations }\end{array}$ & f. test & significance \\
\hline $\begin{array}{l}\text { Between } \\
\text { groups }\end{array}$ & 25.33 & 2 & 12.665 & \multirow{2}{*}{4.95} & no indication \\
\cline { 1 - 3 } Within \\
groups & 218.43 & 85 & 2.56 & \\
\hline grand total & 243.76 & At the level of significance $(0.05=\alpha)$ & \\
\hline
\end{tabular}


Table 10.

\begin{tabular}{|l|l|l|l|}
\hline Economical level & Number & Average & Standard Deviation \\
\hline High & 50 & 13.1 & 2.5 \\
\hline Average & 110 & 13.25 & 2.7 \\
\hline low & 92 & 13.30 & 2.77 \\
\hline
\end{tabular}

Table 11.

\begin{tabular}{|l|l|l|l|l|l|}
\hline $\begin{array}{l}\text { Table (11) } \\
\text { Source of } \\
\text { variation }\end{array}$ & $\begin{array}{l}\text { Sum of } \\
\text { squares }\end{array}$ & $\begin{array}{l}\text { degrees of } \\
\text { freedom }\end{array}$ & $\begin{array}{l}\text { the average of } \\
\text { squares }\end{array}$ & f. test & significance \\
\hline $\begin{array}{l}\text { Between } \\
\text { groups }\end{array}$ & 73.1 & 2 & 46.6 & 2.06 & no indication \\
\hline $\begin{array}{l}\text { Within } \\
\text { groups }\end{array}$ & 1922.31 & 85 & 22.61 & & \\
\hline Total & 1995.41 & 87 & & \\
\hline At the level of significance $(0.05=\alpha)$ &
\end{tabular}

Table 12 .

\begin{tabular}{|l|l|l|l|}
\hline Achievement level & Number & Average & Standard deviation \\
\hline Excellent & 21 & 1.52 & 0.71 \\
\hline Very good & 74 & 1.92 & 0.72 \\
\hline Good & 82 & 2.18 & 0.76 \\
\hline Satisfactory & 42 & 2.14 & 0.74 \\
\hline Weak & 23 & 3.12 & 0.86 \\
\hline
\end{tabular}

Table (12) Shows the level of academic achievement for the study sample as well as and standard deviations

Table 13.

\begin{tabular}{|c|c|c|c|c|c|c|}
\hline $\begin{array}{l}\text { Achievement } \\
\text { level }\end{array}$ & Source & $\begin{array}{l}\text { Sum of } \\
\text { squares }\end{array}$ & $\begin{array}{l}\text { degrees of } \\
\text { freedom }\end{array}$ & $\begin{array}{l}\text { the average of } \\
\text { squares }\end{array}$ & f. test & significance \\
\hline \multirow{2}{*}{ Excellent } & $\begin{array}{l}\text { Between } \\
\text { groups }\end{array}$ & 6.17 & 2 & 3.085 & \multirow{2}{*}{1.22} & \multirow{2}{*}{ no indication } \\
\hline & Within groups & 213.32 & 85 & 2.51 & & \\
\hline \multicolumn{2}{|l|}{ Total } & 219.49 & 87 & & & \\
\hline \multirow{2}{*}{ weak } & $\begin{array}{l}\text { Between } \\
\text { groups }\end{array}$ & 23.55 & 2 & 11.775 & \multirow[t]{2}{*}{4.16} & \multirow[t]{2}{*}{ indication } \\
\hline & Within groups & 241.18 & 85 & 2.83 & & \\
\hline \multicolumn{2}{|l|}{ Total } & 264.73 & 87 & & & \\
\hline
\end{tabular}


Table 14.

\begin{tabular}{|l|l|l|l|l|}
\hline Specialty & Number & Average & Standard Deviation & T test \\
\hline Special Education / Bachelor & 59 & 2.11 & 0.75 & 1.25 \\
\hline Social Service / Bachelor & 62 & 2.18 & 0.72 & 1.33 \\
\hline Delinquency and crime/ Bachelor & 58 & 2.23 & 0.77 & 1.18 \\
\hline Special Education / Diploma & 63 & 2.14 & 0.74 & 1.27 \\
\hline Total & 242 & - & $(0.05=\alpha)$ & \\
\hline
\end{tabular}

Table (14) Shows the averages and deviations of the study sample according to the variable of specialization.

Table 15.

\begin{tabular}{|l|l|l|l|l|}
\hline Specialty & Number & Average & Standard Deviation & T test \\
\hline Freshmen & 103 & 2.51 & 0.93 & 2.03 \\
\hline Sophomore & 75 & 2.32 & 0.70 & 1.98 \\
\hline Junior & 45 & 1.85 & 0.65 & 0.90 \\
\hline Senior & 15 & 1.76 & 062 & 0.78 \\
\hline Total & 242 & - & $(0.05=\alpha)$ & \\
\hline
\end{tabular}

Table (15) shows the averages and deviations of the study sample for the academic year in college.

\section{In the Name of God the Merciful}

Dear students:

The researcher conducted a study entitled (Attitudes of Princess Rahma College Students toward University Violence), so the researcher hopes to answer the questions objectively and with concern, knowing that the information contained in this questionnaire will only be used for the purposes of study and will be dealt with confidentially.

May Peace and God's Mercy and Blessings be upon You.

Researcher

Dr. Khowla Ghneem.

Tick (x) in the option that suits you $\}$ best:

1. Gender: Male. Female.

2 Ages: $18-20$ 21-23 More than 24

3. Income: Low. Average. High..

4. Specialization:

5. Study level: Excellent............ Very Good... Good. Unacceptable:

6. School year: First Seconds:

Third.......Fourth. 
Part two: measurement of the violence attitudes of the students.

Please tick (x) in the place which represents your point of view:

\begin{tabular}{|c|c|c|c|c|c|c|}
\hline NO & Paragraph & $\begin{array}{l}\text { Totally } \\
\text { agree }\end{array}$ & Agree & Neutral & disagree & Totally Disagree \\
\hline 1 & $\begin{array}{l}\text { Scold my fellow students on the most trivial } \\
\text { things when I get angry }\end{array}$ & & & & & \\
\hline 2 & $\begin{array}{l}\text { Things evolve to beating and fighting if I } \\
\text { fought with my fellow students }\end{array}$ & & & & & \\
\hline 3 & $\begin{array}{l}\text { Committed to the reason and manners when I } \\
\text { disagree with my fellow students }\end{array}$ & & & & & \\
\hline 4 & $\begin{array}{l}\text { Frequent problems and disputes between me } \\
\text { and my fellow students }\end{array}$ & & & & & \\
\hline 5 & $\begin{array}{l}\text { Insult my fellow students with the most harsh } \\
\text { words when we disagree }\end{array}$ & & & & & \\
\hline 6 & I push my fellow students when I get angry & & & & & \\
\hline 7 & $\begin{array}{l}\text { My relationships is alienated with my fellow } \\
\text { students }\end{array}$ & & & & & \\
\hline 8 & $\begin{array}{l}\text { I consider myself a violent and aggressive } \\
\text { personality }\end{array}$ & & & & & \\
\hline 9 & $\begin{array}{l}\text { The situations develops to injury when I fight } \\
\text { with my fellow students }\end{array}$ & & & & & \\
\hline 10 & $\begin{array}{l}\text { Fighting sometimes with my fellow students } \\
\text { in issues do not worth more than admonition }\end{array}$ & & & & & \\
\hline 11 & I deliberately embarrass some of my students & & & & & \\
\hline 12 & $\begin{array}{l}\text { Most of the time my relationships is tensioned } \\
\text { with my fellow students }\end{array}$ & & & & & \\
\hline 13 & Moch my fellow students constantly & & & & & \\
\hline 14 & $\begin{array}{l}\text { I do not cooperate with my fellow students in } \\
\text { any situation }\end{array}$ & & & & & \\
\hline 15 & $\begin{array}{l}\text { When I get angry of my fellow students I try to } \\
\text { abuse and humiliate them }\end{array}$ & & & & & \\
\hline 16 & $\begin{array}{l}\text { I have often bring out my violent positions } \\
\text { with my fellow students }\end{array}$ & & & & & \\
\hline 17 & $\begin{array}{l}\text { I despise my fellow students and I consider } \\
\text { them trivial }\end{array}$ & & & & & \\
\hline 18 & I treat my fellow students very roughly & & & & & \\
\hline
\end{tabular}

